\title{
BMJ Open How is the medical assistance in dying (MAID) process carried out in Nova Scotia, Canada? A qualitative process model flowchart study
}

\author{
Ellen T Crumley (10 , ${ }^{1}$ Scarlett Kelly, ${ }^{2}$ Joel Young, ${ }^{3}$ Nicole Phinney, ${ }^{4}$ John McCarthy, ${ }^{4}$ \\ Gordon Gubitz
}

To cite: Crumley ET, Kelly S, Young J, et al. How is the medical assistance in dying (MAID) process carried out in Nova Scotia, Canada? A qualitative process model flowchart study. BMJ Open 2021;11:e048698. doi:10.1136/ bmjopen-2021-048698

\section{- Prepublication history and} additional supplemental material for this paper are available online. To view these files, please visit the journal online (http://dx.doi.org/10.1136/ bmjopen-2021-048698)

Received 04 January 2021 Accepted 09 July 2021

\section{Check for updates}

(c) Author(s) (or their employer(s)) 2021. Re-use permitted under CC BY-NC. No commercial re-use. See rights and permissions. Published by BMJ.

${ }^{1}$ Health, Saint Francis Xavier University, Antigonish, Nova Scotia, Canada

${ }^{2}$ Treasury Board of Canada Secretariat, Ottawa, Ontario, Canada

${ }^{3}$ Dalhousie Medical School, Halifax, Nova Scotia, Canada ${ }^{4}$ Medical Assistance in Dying Program, Nova Scotia Health Authority, Halifax, Nova Scotia, Canada

${ }^{5}$ Neurology, Faculty of Medicine, Dalhousie University, Halifax, Nova Scotia, Canada

Correspondence to Professor Ellen T Crumley; ecrumley@stfx.ca

\section{ABSTRACT}

Objectives The aims of this study are: (1) to create a flowchart process model of how medical assistance in dying (MAID) occurs in Nova Scotia (NS), Canada and (2) to detail how NS healthcare professionals are involved in each stage of MAID. The research questions are: how is the MAID process carried out and which professionals are involved at which points? and which roles and activities do professionals carry out during MAID?

Design Qualitative process model flowchart study with semistructured interviews.

Setting Primary and secondary care in NS, Canada. Participants Thirty-two interviewees self-selected to participate (12 physicians, 3 nurse practitioners (NP), 6 nurses, 6 pharmacists and 5 healthcare administrators and advocates). Participants were included if they conduct assessments, provide MAID, fill prescriptions, insert the intravenous lines, organise care and so on.

Results The flowchart process model details five stages of how MAID occurs in NS: (1) starting the MAID process, (2) MAID assessments, (3) MAID preparation (hospital inpatient, hospital outpatient, non-hospital), (4) day of MAID and (5) post-MAID (hospital in-patient and outpatient, non-hospital, after leaving setting). Nineteen points where the process could stop or be delayed were identified. MAID differs slightly by location and multiple professionals from different organisations are involved at different points. Some physicians and NP provide MAID for free as they cannot be reimbursed or find it too difficult to be reimbursed.

Conclusions Our study adds knowledge about the MAID activities and roles of NS professionals, which are not documented in the international literature. Clinicians and pharmacists spend significant additional time to participate, raising questions about MAID's sustainability and uncompensated costs. The process model flowchart identifies where MAID can stop or be delayed, signalling where resources, training and relationship-building may need to occur. Knowing where potential delays can occur can help clinicians, administrators and policymakers in other jurisdictions improve MAID.

\section{BACKGROUND}

Medical assistance in dying (MAID) has been legal in Canada for over 4 years. ${ }^{12}$ Although
Strengths and limitations of this study

- Our novel flowchart process model of medical assistance in dying in Nova Scotia, Canada outlines professionals' roles and activities, the points at which they are involved and where delays/stops can occur.

- Our findings from Nova Scotia, Canada provide an opportunity for other jurisdictions to learn how medical assistance in dying works as well as compare and contrast their model.

- As this study occurred in one Canadian province, Nova Scotia, it does not enable us to generalise the findings to other provinces or internationally.

MAID includes both assisted suicide and euthanasia, most Canadians have chosen euthanasia. ${ }^{3}$ Many of the initial ad hoc processes and procedures that healthcare professionals developed to implement it while professional College policies, health authority policies and processes were being developed are still being used today. ${ }^{4-9}$ In 2017, when the MAID process was first being set up, the press described it in the provinces of Ontario and Nova Scotia (NS), respectively, as:

an ad hoc, scattershot mess. Policies were hammered out in email chains and over casual conversations $^{10}$

We have a small set of providers, but we can't possibly keep up with the patient demand. ${ }^{11}$

It is difficult, however, to evaluate and improve a new health service without understanding how it is carried out. Canada's MAID criteria are currently being debated and the legislation may be expanding: advance consent for those who will lose capacity may be included and the 'reasonably foreseeable' death requirement may be removed. ${ }^{12-15}$ The latest national poll found Canadians support advance consent (82\%) 
and removing 'reasonably foreseeable' $(71 \%)$ in the legislation. ${ }^{16}$ Thus, there is a pressing need to evaluate and improve the process. The objectives of this study are to create a flowchart process model of how MAID occurs and detail where and how healthcare professionals are involved in NS's process. Our research questions are: how is the MAID process carried out and which professionals are involved at which points? and which roles and activities do professionals carry out during the MAID process?

Many of today's healthcare services are designed around interdependent roles- that is, professionals organise interdependent work around their responsibilities and activities. ${ }^{17}$ Process theory examines the sequences and stages of activities and events as they occur. ${ }^{18-20}$ Some processes emerge as they are implemented and may not be written down, causing an issue for quality improvement. With MAID, events such as appointments often occur in a linear fashion, that is, in a certain order, and a person requesting the service needs to meet specific criteria in order to move from one stage to another. ${ }^{18}$ Internationally, there is little documentation about how MAID occurs, which professionals are involved at which points and how the process is organised.$^{21}$ The eight jurisdictions that have assisted suicide and/or euthanasia, Australia (Victoria and Western Australia recently legalised assisted suicide and euthanasia), Belgium, Canada, Colombia, Luxembourg, The Netherlands, Switzerland and eight states in the USA, ${ }^{22}{ }^{23}$ collect descriptive statistics about number of deaths, gender and so on. However, additional data are needed to evaluate and improve the service (eg, feedback from providers, patients and families, analyses of the process including its policy, functionality, efficiency, effectiveness, impacts and sustainability and so on). ${ }^{24}$

Canadian providers and health systems are actively working to improve the MAID experiences of patients, families and professionals, ${ }^{25-28}$ but it remains challenging to improve its implementation without knowing what the process looks like. Studies describing professional roles, expectations and knowledge gaps ${ }^{9}{ }^{15} 29-32$ or how MAID was implemented ${ }^{4} 5933-37$ provide few details about the process itself (eg, how work is coordinated between professionals, which professional(s) do which activities and when and so on). ${ }^{14}{ }^{21}{ }^{37-41}$ The process involved in the provision of MAID in one province can help us better understand how new health services are implemented. Our identification of gaps and inefficiencies in the process is timely given that lawmakers will be expanding eligibility criteria for MAID, yet the number of physicians and nurse practitioners (NP) that provide it is not growing in NS. ${ }^{42}$ National best practice guidelines and training are available. ${ }^{38}$ Patients, health professionals and policymakers want to improve the MAID service. ${ }^{40} 41$ This study provides details about how the MAID process is being implemented in NS, from beginning to end, and identifies areas for improvement.
METHODS

\section{Design and setting}

A qualitative process model flowchart study for MAID was conducted in the province of NS in Canada because MAID is centrally coordinated and the researchers reside there. As the lead researcher specialises in interviews, first-hand accounts from those involved in MAID were the most appropriate to piece together how the process occurs. Using semistructured interviews, we asked those involved in the MAID process (eg, assessors, providers, administrators) to describe their roles, activities and at what points they are involved. ${ }^{184344}$

\section{Recruitment and sample}

Participants were recruited through: (1) emails to the NS MAID providers' list-serv (convenience sample), (2) emails to professional colleges, associations and organisations and (3) snowball sampling ${ }^{45}$ by asking authors and participants to forward study information to colleagues involved with MAID.

The sample included health professionals who are involved in MAID: physicians and NP (hereafter, clinicians), nurses, pharmacists and health administrators. Data were securely collected and stored using the approved protocol. Participants received written study information and completed an electronic or written consent form. To ensure confidentiality, participant characteristics are presented at a group level, and quotations are anonymised by profession and interview number.

\section{Data collection}

ETC collected data from 29 participants using a semistructured, pretested interview guide in-person in a private location, by telephone or Microsoft Teams (see online supplemental file 1). JY, a medical student, was trained by ETC and conducted three of the interviews under her supervision. The interview guide was pilot tested with three clinicians. To obtain details about how and when they are involved and their interactions with other professionals, participants were asked open-ended questions about their MAID role and activities. ${ }^{46}$ Interviewers probed participants' responses by asking follow-up questions and also made field notes. Interviews were audiorecorded, professionally transcribed in simple verbatim (eg, um, ah and pauses were not transcribed) and stored in password-protected Microsoft Word documents on a secure server. ${ }^{47-49}$ As JM is the Medical Affairs Advisor (MAA), NP is the MAID Nurse Navigator (MNN), GG is a MAID provider, they were not involved in data collection to help preserve participants' anonymity. To achieve saturation, data were collected until no new information about the process was found.

\section{Data analysis}

After each interview was completed, data were iteratively coded and checked using constant comparison during six phases: ${ }^{4850}$ (1) reading each interview and coding passages about MAID roles, activities and stages; 


\begin{tabular}{ll}
\hline Table 1 Participant characteristics & \\
Type of professional & $\begin{array}{l}\text { Number (\%) of } \\
\text { participants n=32 }\end{array}$ \\
\hline Physicians & $6(18.8)$ \\
\hline Family medicine & $4(12.5)$ \\
Palliative care/critical care & $2(6.3)$ \\
Emergency medicine & $3(9.4)$ \\
\hline Nurse practitioners & \\
\hline Nurses & $3(9.4)$ \\
\hline Hospital & $1(3.1)$ \\
\hline Long-term care/nursing home & $2(6.3)$ \\
VON & \\
\hline Pharmacists & $2(6.3)$ \\
\hline Community & $4(12.5)$ \\
\hline Hospital & $5(15.6)$ \\
\hline Health administrators/advocates
\end{tabular}

VON, Victoria Order of Nurses.

(2) creating a draft flowchart process model with stages and outlining professionals', roles and activities in each stage; (3) continuing to conduct and code interviews, then incorporating new or revised information into the draft flowchart process model (drawn using Microsoft PowerPoint); (4) inviting all participants to critique the flowchart process model and incorporating their recommendations and changes; (5) finalising the flowchart process model and (6) writing the article.

\section{Patient and public involvement}

Patients and or public were not involved in this research.

\section{RESULTS}

Thirty-two professionals participated in 1-2 hour interviews (table 1). Figure 1 has the process model detailing professionals' MAID roles and activities as well as the places where the process may stop or be delayed, depicted by a red octagon. Box 1 has quotes about how NS professionals' view the MAID process and their role.

\section{STARTING THE MAID PROCESS}

Patients explore MAID for many reasons ${ }^{3751-53}$ and often find out about it through the media, Dying with Dignity (DWD), a "national human-rights charity committed to improving quality of dying, [and] protecting end-of-life rights, ${ }^{54}$ or the Nova Scotia Health (NSH) website. When they are exploring MAID, NS patients may do their own research, call the MNN or visit a clinician (eg, family clinician, surgeon, nurse practitioner) to obtain more information. The clinician may give a patient MAID information or send a patient referral to the MNN. Some patients may first seek information about MAID, then visit a clinician again for a MAID assessment referral. If the clinician has a conscientious objection or is not comfortable participating in MAID, they will transfer the patient to another clinician, send a referral to the MNN or ask the patient to contact the MNN. If the MNN does not receive a referral, they will follow-up with the clinician. One physician suggested this could be improved by having 'a self-referral system. And it doesn't need to involve family doctors'. An administrator also noted that:

My biggest concern is there are people who want MAID but they are unable to access the system because the doctors won't put their names forward. We have had phone calls of people that said my doctor won't refer so we had to call them [doctor] back and explain that there is a duty to transfer the name of a patient requesting and they shouldn't disallow the request to occur. (Admin 3)

The MNN's role is central. As paperwork or phone calls are received, the MNN contacts the patient for an intake interview to explain the MAID process, offer support, explain resources (ie, palliative care, home care) and seeks to understand the patient's goals. The MNN may email or mail the patient information (eg, Advanced Directive Guides, MAID and Palliative Care information). The MNN sends MAID documentation (eg, referral, nursing intake notes, clinical notes) to assessing clinicians. The MNN remains in contact with the patient, family and their circle of care throughout the process. One administrator detailed the process:

Referrals come in typically from family doctors but occasionally specialists ... the patient arrives at a point where they are considering MAID as an option and discuss that with their physicians ... So the physicians would make referrals to this office $[\mathrm{MNN}]$. It's generally faxed to us ... And I get the referral. I'll capture the basic patient information that is required as part of our reporting to the federal government.... and then inform the MAID provider team. ... a group of physicians, nurse practitioners ... who do the assessments and perform the procedure.... through an email. (Admin 2)

At any time, patients may decide not to continue with MAID and pursue options such as palliative care; patients may pursue multiple options simultaneously. If the clinician the patient initially visited will not do the first MAID assessment, the patient or clinician contact the MNN who helps streamline and organise the process. As discussed in the quote above, the MNN then emails the NS MAID list-serv to request assessors. Finding assessors may take time due to the small number of NS clinicians who participate in MAID, their lack of time and/or their inability to travel. Some clinicians will only assess their own patients but do not provide MAID. Some clinicians said patients must bring up MAID, not them, suggesting the NSH needs to educate clinicians about how the process works. As one nurse practitioner said 'I only bring up MAID if they ask me about it. Like if a patient comes in and wants 
Starting the MAID Process

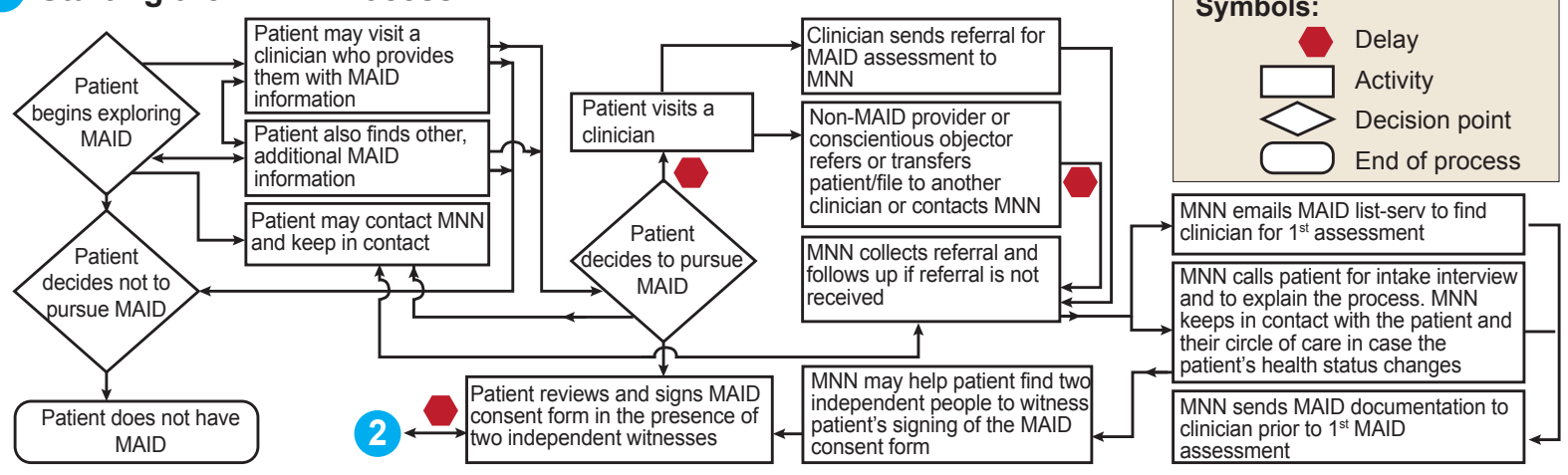

2 MAID Assessment

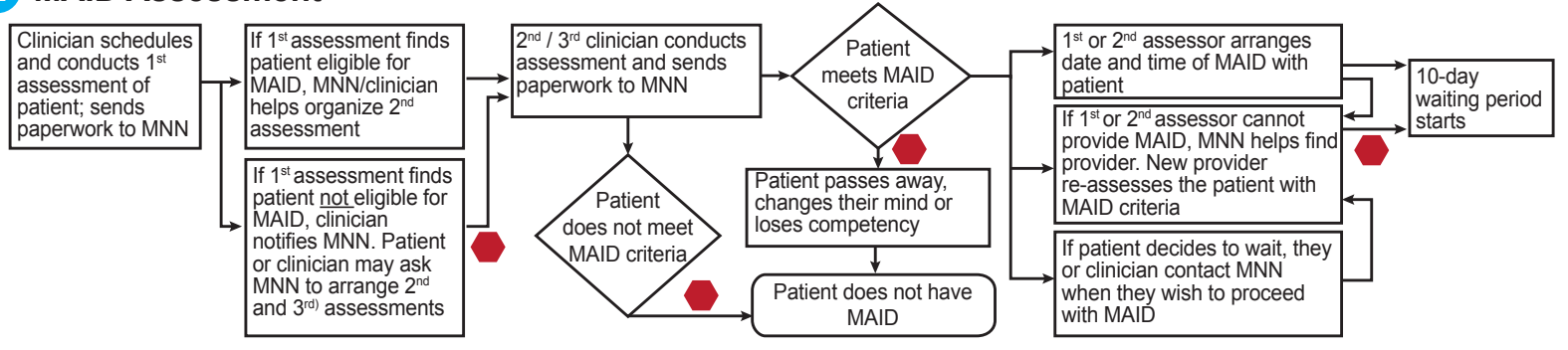

\section{MAID Preparation}

\section{A Hospital In-Patient}

\begin{tabular}{|l|l|}
\hline $\begin{array}{l}\text { Clinician or MNN asks } \\
\text { staff for help coordinating } \\
\text { the procedure. The } \\
\text { patient might be in or } \\
\text { moved to a private room } \\
\text { for MAID. The MNN may } \\
\text { provide MAID support and } \\
\text { education for ward staff. }\end{array}$ \\
$\begin{array}{ll}\text { Clinician asks nursing stafi } \\
\text { comfortable with MAID to } \\
\text { insert two IVs and collect } \\
\text { supplies }\end{array}$ \\
\hline
\end{tabular}

\begin{tabular}{|c|c|}
\hline $\begin{array}{l}\text { Clinician, hospital } \\
\text { staff and MNN } \\
\text { coordinate } \\
\text { hospital staff and } \\
\text { location for MAID } \\
\text { procedure. }\end{array}$ & \multirow{2}{*}{$\begin{array}{l}\text { Clinician orders MAID } \\
\text { medication from } \\
\text { hospital pharmacy, } \\
\text { which typically needs } \\
24-48 \text { hours notice. If } \\
\text { no hospital pharmacy, } \\
\text { MNN will coordinate } \\
\text { with another } \\
\text { pharmacy. }\end{array}$} \\
\hline \multirow{4}{*}{$\begin{array}{l}\text { 2-5 Pharmacists } \\
\text { prepare and } \\
\text { double-check the } \\
\text { two MAID } \\
\text { medication kits }\end{array}$} & \\
\hline & $\downarrow$ \\
\hline & $\begin{array}{l}\text { Clinician asks nursing } \\
\text { staff comfortable with }\end{array}$ \\
\hline & MAID to insert two IVs \\
\hline
\end{tabular}

Day of MAID

\begin{tabular}{|c|c|c|c|c|}
\hline $\begin{array}{l}\text { Clinician picks up } \\
\text { medications from } \\
\text { pharmacy }\end{array}$ & $\begin{array}{l}\text { Clinician arrives (may be at } \\
\text { location or fly/ drive/walk } \\
\text { there) }\end{array}$ & $\begin{array}{l}\text { Clinician } \\
\text { assesses } \\
\text { patient }\end{array}$ & $\begin{array}{l}\text { Patient choses not } \\
\text { to have MAID or } \\
\text { has lost capacity }\end{array}$ & $\begin{array}{l}\text { Patient does not have } \\
\text { MAID }\end{array}$ \\
\hline & $\downarrow$ & $\begin{array}{l}\text { capacity, } \\
\text { then obtains }\end{array}$ & & \\
\hline $\begin{array}{l}\text { Clinician obtains } \\
\text { MAID supplies (e.g. } \\
\text { syringes, needles) }\end{array}$ & $\begin{array}{l}\text { Nurse inserts } 2 \text { IVs and may } \\
\text { stay for procedure. Clinician } \\
\text { may also insert } 2 \text { IVs. }\end{array}$ & $\begin{array}{l}\text { patient } \\
\text { consent for } \\
\text { MAID }\end{array}$ & $\begin{array}{l}\text { Clinician } \\
\text { administers MAID } \\
\text { medications }\end{array}$ & \\
\hline
\end{tabular}

5 Post-MAID

A Hospital In-Patient and Out-Patient

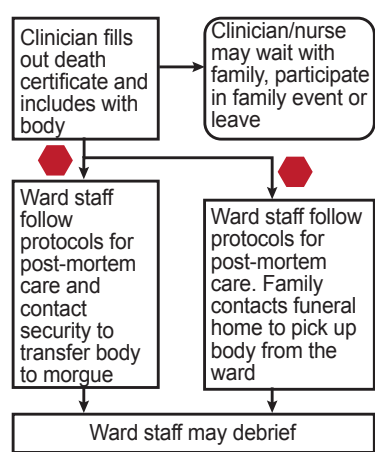

B Non-Hospital

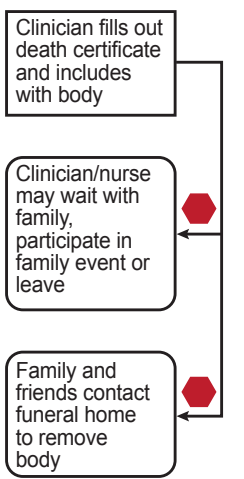

\section{After Leaving Setting}

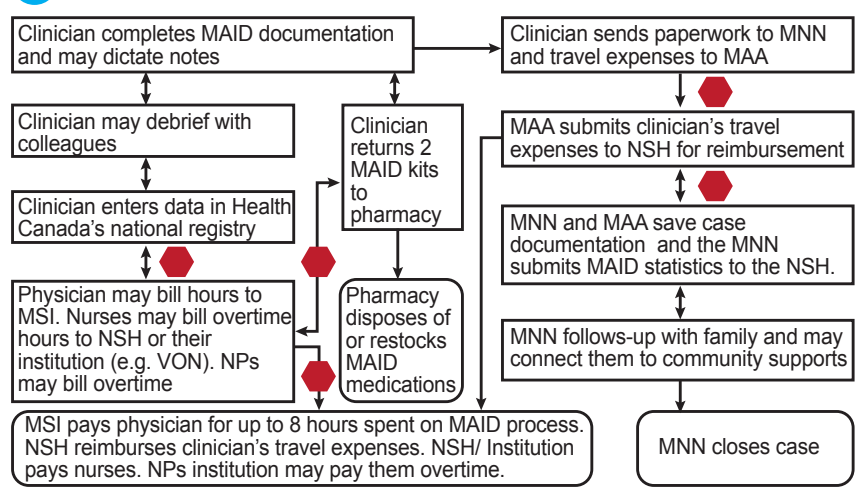

Figure 1 The MAID process in NS, Canada. MAID, medical assistance in dying; MNN, MAID Nurse Navigator; MSI, Medical Service Insurance; NP, nurse practitioners; NS, Nova Scotia; NSH, Nova Scotia Health; VON, Victoria Order of Nurses. 
Box 1 Professionals' quotes about the MAID process

\section{Logistics and scheduling}

'when MAID came up, I thought 'well it's legal!'. ... people have the right to ask for this and nobody in my community was willing to provide this service. I knew that I couldn't be available to do the actual procedure, $\ldots$ and facilitating the actual procedure of coordinating ... the healthcare team members. ... there's this huge reliance on pharmacists and nursing staff and community funeral homes and so on, to be sure that the whole procedure is done properly. ... at that time, I was one of two people who would do a MAID consultation.' (Physician 8)

'I don't do IVs [intravenous lines] very often. So worrying that I was going to go to this house to do a MAID procedure and not be able to get the IV [intravenous line].' (Physician 11)

'procedures can be done within a half hour to 40 minutes. I go in and have a chat with them and make sure that they still have capacity and that they know why I'm there. And if they still want the procedure. I'll say, okay, have some time with your family or whoever is there. And I'll go get my medications ready, and then I'll come back and ask them again if they want me to proceed or give them that last chance to rescind.' (Physician 12)

'there's a fair amount of phone calls and logistics. So if I've agreed to do the provision for a patient, so l've had to do one of the assessments and if ... they've had two assessments that agree that they meet the criteria, then I ask the patient to decide on a time and a place, and we talk about when and where that might be ... So if it's at home it's easy ... If it's not at home, it means having a patient admitted to the hospital or going through ambulatory care, then that would take phone calls and arranging. ... I don't like to be fumbling in somebody's dark bedroom with big syringes and vials and so I have a system, I get it all ready in my office. I have a plastic tote ... and all the paperwork ... So, I like to have it all ready to roll and then I arrive at the patients home ... the morning of the procedure. After the procedure I have to sign the death certificate and do the paperwork ... and then return the unused medications to the pharmacy. So there's a fair amount of ... little detailly stuff.' (Nurse Practitioner 1)

'In our first [MAID] case ... a CCA [Continuing Care Assistant] had struggles. ... We respect people's decisions all of the time. ... And so perhaps our staff are better prepared because of those autonomous choices, like we have ethical conversations around them, when people make decision to not have treatment or suspend treatment and how do we support staff at that point ... something that we may struggle with is probably making sure the staffs' schedule of that [MAID] day are aware of personal values. So if we had a Muslim RN, we have to change shifts. It is being conscious of that from an administrative staffing scheduling perspective that we had thought 'We don't put people in difficult situation". (Admin 1)

'If I get a call now and somebody says there's a MAID case and they're interested in whatever date, I really have to drop everything and try to organize the space, the date, the staff.' (Admin 4)

'The drugs themselves are often in pharmacies, just not either in the quantity or the dosing that we need.' (Pharmacist 1)

\section{Process}

'When I'm assessing somebody, I'm usually generating the consult, right. The patient's come to me. I've seen them. I've said, okay, I'm going to be the assessor 1. Off to you guys - you find assessor \#2, and, you know, deal with all the rest of it.' (Physician 7)

'I provide them [clinicians] basic information about the case. And then they would get back to me ... "I'll take this case" ... I do the assignments of physicians to the case, forward patient information ... about

\section{Box 1 Continued}

the referral. They will do the assessment and then report back to me. And I will arrange for the second assessment to take place ... Once those assessments agree that ... the patient meets the criteria for the MAID, we would walk the patient around the details of time, location, circumstance for the procedure. So then the procedure happens and the physicians and nurse practitioners take care of the specific details relative to the location and the medication protocol ... the procedure is completed and practitioners send the information to me and I capture that in the office and then close the case.' (Admin 2)

\section{Relationships}

'they're such neat patients, and their families are so neat, and the initial interview ... you get to know them so much, you talk about their life and you get to know where their moral compass lies and what their general feelings about life and death and suffering and quality are. And the family often really wants you to know and love that person the same way that they do, so you get a lot of that background in a really short period of time. And then typically I do my procedure on a different day, and so going back in to meet the family again and see them for the procedure, there's often so much relief to see you and they're so pleased.... sometimes if the patient has some sort of functional decline or symptom management issues in between, you've talked to the family a few times to help them navigate that and make sure that their quality is maintained while they're waiting for their procedure, so I think you become attached to the families very, very quickly.' (Physician 9)

\section{Time and compensation}

'When you go to see a patient, you never know if it's going to be a half hour assessment or a 2 hour assessment.' (Physician 3)

'Each MAID case is taking probably a minimum of 5 or 6 hours of time. That's 5 or 6 ... patients that I could see in that time. So we were never resourced to consider taking on MAID. And that's probably the most practical issue.' (Physician 5)

'the procedure itself is fairly quick once everything is set up. But generally it takes hours in order to go through this very personal process with this individual. Sometimes they're very straightforward. Other times... You know, l've heard stories of very elaborate events that have been planned around medical assistance in dying. ... I am astounded and I'm stunned by the clinicians that will do this on a regular basis and take hours and hours and hours of their personal time.' (Physician 6)

'about 5 to 7 hours. And that [putting together first MAID kit] was over several days. And that was a process of, you know, calling places, calling the other pharmacy, finding the drugs, calling our wholesaler to find out if we're ordering the right ones, data entering the information, getting the bins together, you know, with labelling. Making sure we have a spot in the fridge. Making sure all of our staff are aware. Like it was a very time-consuming endeavour.' (Pharmacist 2)

\section{Policy and legislation}

'I went out and I got the [MAID] policies ... But there was no meaning in them. But once we had the [MAID] requests, I had two months. But I had already written the paper and I had already kind of went through all of that. ... I just basically stole the policies and procedures from [location] and [location] and another [location] and put them all together.... The mechanics weren't the important thing. It was getting the fact sheet right and getting to that audience, that you could talk to them in their language.... For me it was the relational piece that was more important than the mechanics.' (Nurse 1)

'I think Canada can have the absolute best assisted dying regimen in the world. We can show people how it can be done, how it can be done

Continued 


\section{Box 1 Continued}

well. And we just need to make some changes to do that. ... I'm in a transition in the sense that I have to recognize there's some things that are my wheelhouse and there are a lot of things related to this [MAID] that are not my wheelhouse and I need to let others do it, right. For a long time I was pretty alone in this field, trying to make this change. And so you just feel like, "Oh, it's on my shoulders. I've got to keep going, I've got to keep doing it". And at the first CAMAP [Canadian Association of MAID Assessors and Providers] meeting, it was the most extraordinary feeling because I was ... with all these people and this is what they do. And it was this incredible sense of relief and release and a sense of okay, you know, this is in good hands. ... So now what I try and focus on are the things that I can do.... there's an issue right now of whether nurses can raise the issue. ... Or the faith-based institutions, publicly funded faith-based institutions ... there's a way in which it's my wheelhouse.' (Admin 5)

\section{Role}

'I've been involved with MAID two more times. ... I don't want to do the second assessment. ... I did it [once], and I am okay with that. And I don't have any moral distress with it. Even though I get choked up about it, it's only because I remember the patient, and I remember how deeply I felt about [them] and helping [them] die comfortably. ... if we're going to be providers, we have to help people get access to what they want, even if we, because of our beliefs, our faith would not do that ourselves. ... I wouldn't want to go any deeper down a road than first assessment...' (Nurse Practitioner 2)

'As a nurse, I can't push those drugs. I can't order the drugs. I can't go and get the drugs. I can't push the drugs. So I am there as a patient support and a family support.' (Nurse 4)

'Technicians are not involved with this [MAID prescriptions] at all. ... So other orders, ... I send pretty much through the system to the technicians to say send this to the floor. ... And then the technicians take it from there. With the MAID, it's 100\% pharmacist-run. So we enter the prescriptions that were ordered and then we're picking up the labels, we're packaging it up and we're checking it. ... Let's just say I'm the pharmacist who checked it [MAID prescription]. ... Usually it's the clinician who picks it up but there are a few options. But because we can't leave the dispensary, usually the clinicians are okay to come and get it. And then there's additional information we need to provide, education ... and basically we go through the medications.' (Pharmacist 5)

\section{Secrecy and privacy}

'we were under the impression that we weren't supposed to be sharing the fact that we are participating in it with coworkers and things like that. So there's not a lot of ... interprofessional support. And we were encouraged to do that just because they didn't want the public knowing like where things were taking place ... it was presented to us as like, "Well, there might be a death notice in the paper and someone might put together that you just participated in this thing. So that's what that family chose. So it's really important to not tell anyone that you... because their decision needs to be kept private." Which I understand. But it does make it difficult to process.' (Nurse 5)

'So basically what we were told when MAID became law was that if patients voiced wanting more information about it, you know, we don't really have an opinion per se because... You know, I don't know if my coworkers are for or against.' (Nurse 6)

'I also regard it [MAID] as a very private confidential process. And I know we've really struggled with that in the distribution side ... whether it should be at a higher level of confidentiality than everything else we do. And everything we do is confidential. But if one person is handling

Continued

\section{Box 1 Continued}

a MAID, do all 5 pharmacists in the dispensary need to know about that MAID? ... clinically I am not required to counsel the patient. They haven't asked me to do that, and they didn't, you know, tell me of this decision. That may have been the intent, you know. But at the same time ... it's part of the therapeutic plan that wasn't well documented like every other process that we work on as a team is.' (Pharmacist 4)

MAID, medical assistance in dying.

to know about MAID, I'll explain it'. If a patient mentions MAID to staff, they will refer the patient to a clinician, the MNN or a manager in their facility.

Although clinicians and the MNN prefer the MAID consent form is signed after the first assessment, some patients download it from the NSH website and sign it in advance. As patients are often quite ill, they may have difficulty finding two independent witnesses to observe them signing the MAID consent form. To find independent witnesses, the MNN will contact DWD which has a national network of volunteer witnesses. If the MAID consent form is not signed before the first assessment, the clinician will give it to the patient. Two physicians shared their experiences with consent:

I go through the consent and kind of the little conundrums or difficulties with getting consent (Physician 10)

Sometimes the patient has signed their request. Other times they're waiting and trying to get witnesses lined up. So most times when I'm involved, I've assessed them, I'm usually not there when witnesses are signing. But they're making the request. (Physician 7)

Delays can happen if patients have to wait for an appointment with a clinician to discuss MAID. If a patient initially meets with a non-MAID provider or conscientious objector, they have to be referred/transferred to another clinician and make another appointment, which could delay their assessments. A common delay is finding two independent people to witness the consent form signing.

\section{MAID ASSESSMENTS}

The clinician arranges the patient's first MAID assessment and continues communicating with the MNN. This assessment can occur in the patient's home, hospice, hospital, nursing home or clinician's office. Assessments can take 45 min to 5 hours depending on the location and the case complexity. As one physician described:

if it's an in-house assessment, I'll schedule it for the late afternoon/evening, like starting at 4:30 or 5:00.

And then it goes until about 6:30 or so. (Physician 12)

The first assessor discusses the MAID process with the patient (and their family and/or supports, depending on the patient's wishes), including legislation, criteria and timeline. The clinician also provides the patient with the 
College of Clinicians and Surgeons of Nova Scotia Professional Standard Regarding Medical Assistance in Dying. The clinician completes the MAID assessment form, sends it to the MNN and may dictate notes for their records:

I had no difficulty whatsoever doing the ... MAID 1 or MAID 2 [assessment]. And then I was having the conversations, discussing if the people met the criteria as outlined by our licensing body in Nova Scotia, and ... completing the paperwork. (Physician 8)

so there's the assessment piece, we have a checklist form that we fill. But it doesn't give enough history. So most of us will dictate a note. ... Both assessments and the consent all have to get copied and sent into the central office for MAID. So they have to have a record of it. Which is nothing but it's still paperwork that has to happen. (Physician 3)

If the first assessor finds the patient is not eligible for MAID, the patient may ask the MNN to arrange a second and third assessment. If the second and third assessors indicate the patient is ineligible for MAID, the process is finished in NS. Although it is more rare, some patients may go to another province or country to be assessed for assisted dying or euthanasia eligibility.

If the first assessor indicates the patient is eligible for MAID, the MNN or clinician arranges the second assessment. The second assessor often provides or reviews the consent form, returns their assessment form to the MNN and may dictate notes. If both assessments indicate the patient meets MAID criteria, the patient decides when MAID occurs-it could occur hours, days or months later. Sometimes, neither assessor provides MAID, the patient decides to wait, the original assessors are not available or the patient requests MAID during a busy time (eg, summer or December). If MAID is delayed for a significant amount of time or another provider is needed, the MNN helps find a provider to reassess the patient to ensure they still meet MAID criteria. When patients decide to wait, the MNN checks in with them and receives regular updates from their circle of care. The MNN keeps relevant healthcare providers informed about the patient's goals and health status.

Numerous delays can occur or the process could end during this stage. If the two assessors do not agree a patient meets MAID criteria, a third assessment will be done. The process stops if a patient does not meet MAID criteria, dies, changes their mind or loses competency. As Physician 11 describes, the 10-day waiting period can be waived for patients about to lose capacity or their imminent death and MAID will be provided before the 10 days have passed:

two days after the [MAID] Assessment, the family phoned and said, 'Come now. You know, he's starting to get confused.' ... And then there was a brief ... kerfuffle getting the other assessor to agree to move it up, and scrambling to learn how to get the drugs from the drugstore. And tried to get the VON in, and it being too late-the nurses do the IV [intravenous line]. And then going and stealing IV [intravenous line] equipment from the emergency department. (Physician 11)

If the first or second assessor cannot provide MAID, it may be delayed while the MNN finds another provider, who then may need to reassess the patient.

\section{MAID preparation-hospital in-patient}

For in-patients, the clinician and MNN ask hospital staff (eg, a nurse manager, nurse director) to find a private room and a nurse comfortable with the two intravenous lines for MAID, one to be used and one backup. The two intravenous lines are usually inserted by a hospital nurse who also gathers supplies (eg, syringes, needles, intravenous solution, intravenous pole, tubing and so on). The clinician alerts the hospital pharmacy about the upcoming procedure and sends a preprinted MAID order (PPO). If the hospital does not have a pharmacy, the pharmacy does not have the medications or the pharmacist(s) will not fill the PPO, the MNN and/or clinician will coordinate the MAID medications with a community or another hospital pharmacy. The other pharmacy may courier medications to the hospital. Two to five pharmacists fill the MAID PPO which is time-consuming for several reasons: shift changes (ie, the MAID PPO may be partially filled when the shift changes), MAID PPO are filled in-between regular work (ie, another pharmacist may take over the PPO if the other one is busy) and the two sets of medications need to be double-checked according to pharmacy protocol. ${ }^{51}$ Because NS pharmacy technicians cannot fill the MAID PPO, this results in additional work for NS pharmacists:

the biggest thing is actually doing the collecting of the drugs ... I would never be the one to go and collect the drugs and ... put them together in the bags. That would usually be a technician job after a pharmacist okayed the order and felt comfortable with it, and said, 'Okay, these are the drugs that we're using. Proceed with this'. But in this step [MAID PPO], we're actually the ones who are collecting the drugs as well. ... we do keep everything [MAID medications] like actually in a box. So we don't have that initial like trying to make sure that the drugs are appropriate. We do have them for when MAID orders do come up. So we have them separated. (Pharmacist 3)

The time to fill a MAID PPO is significant and pharmacists receive no additional compensation (ie, community pharmacists receive a small dispensing fee but hospital pharmacists do not):

I can do a regular order in probably 20 seconds, depending how easy it is. A MAID can be like well over an hour. (Pharmacist 6)

Two MAID medication kits are prepared in case anything unforeseen occurs (eg, broken bottle). Clinicians typically pick up the medications $24-48$ hours after the PPO 
is submitted, but pharmacies may make exceptions for urgent cases. For patients preferring anonymity, a ghost/ shadow chart may be used to conceal their identity.

\section{MAID preparation-hospital outpatient}

A nurse manager, charge nurse, facility lead or MAID provider helps ensure outpatients are registered and admitted, a location is identified and staff are coordinated. Some hospitals have specific wards or rooms for MAID outpatients after hours since these are often used during the day:

we have a place ... if people want to just come in and have it [MAID] done in hospital. So we've done a number that way as well. ... We tend to do it after hours. We have a clinic area that's got some nice rooms. And so we tend to do it after hours when they're not busy. And it's a nice room. Families can be there. (Physician 3)

A hospital nurse often inserts the intravenous lines and gathers MAID supplies; an anesthesiologist may insert the intravenous lines. The MNN may provide support and MAID education to ward staff. The same pharmacy processes and ghost charting occur as in Section 'MAID preparation-hospital in-patient'.

\section{MAID preparation-non-hospital}

MAID may also occur in the community (ie, a patient's home), long-term care, nursing home or a hospice. A lot of coordination and steps are involved:

If somebody was at home ... I would send the prescription in to the [community] pharmacy, call the pharmacist and make sure it was received. I would fax requests into VON for the IV's [intravenous lines] to get inserted the day of the planned procedure. ... I would coordinate this with the patient and their family to make sure that the time and place was all arranged, and they wanted to go ahead. I would pick up the medications at the pharmacy, I would usually prepare them here in my office so that when I arrive at the patient's home everything is all drawn up. (Nurse Practitioner 1)

The clinician and MNN often work together to contact Continuing Care (ie, the Victoria Order of Nurses (VON)) to insert the intravenous lines. A VON nurse manager will find a nurse who does not have a conscientious objection to inserting the intravenous lines. One nurse described the intravenous lines:

It's not a simple IV [intravenous line]. It's not a little tiny one. You have to be able to... to put an intravenous line in that is as big as an anesthetist would use. So big. (Nurse 3).

Typically, MNN sends all the MAID docs to VON and confirms they can meet the need. A VON manager provided details: when we get a referral come in for MAID ... we break it down into 4 areas, there's a nurse manager for each area. So we take the referral and work with Continuing Care to ensure that ... the consents are there, that we have everything we need. And then we go through the client's schedule ... to find a nurse that has been there the most so that we can have somebody that the client or the family knows. And then we reach out to the nurses to see if they are willing to participate. Because it's their choice to do it. And I'd say probably $60 \%$ are willing. (Nurse 2)

The clinician coordinates the medication order with a community pharmacy and may discuss further with a pharmacist unfamiliar or uncomfortable with MAID. One to three pharmacists prepare and double-check the two MAID medications. The clinician usually picks up the MAID medications 24-48 hours later. If the pharmacy does not have MAID supplies and the clinician may obtain these from their hospital or facility. The MNN and MAA are currently working on making MAID kits available for all clinicians.

In stage 3 , there may be delays if a nurse cannot be found to insert the intravenous lines or the hospital pharmacy will not fill the PPO. The clinician or MNN may need to coordinate with another pharmacy or find a willing pharmacist. MAID may be delayed

\section{Day of MAID}

Depending on where MAID is occurring, the MAID process can take several hours:

some of the cases are straightforward. You know, it's in the hospital, you go in, the assessment takes an hour, you come out, you give the order to the pharmacy, the nurse is ready, you come back for the procedure, it takes an hour. ... But some cases, especially if they're at home or they're in the periphery, are very complex.... you have to be coordinating with VON to get the IV [intravenous line] set up and the pharmacy - which has probably never had to organize the medications. And then getting back and forth with the patient as they sort of progress and checking in on how they are.... And then the driving (Physician 2)

The clinician picks up the MAID medications from the pharmacy and gathers supplies. They may drive to the patient's location and, in some cases, fly or walk. Some may participate in religious services, celebrations of life or farewells before or after MAID, but not all clinicians are comfortable with this. As one physician recounted:

the procedure takes about 15 minutes. That's the actual giving of the medications. But between getting the medication...picking up the medications, drawing everything up, getting yourself ready to do the procedure, going in, seeing the family, making sure they're all set and ready to go, it usually takes about two hours or so. ... Sometimes you go in and ... they don't want to chat, they just want to go and 


\section{Box 2 Medications used for MAID in NS}

- First medication: a sedative to help relax the patient. The patient typically falls asleep in 30-60 s.

- Second medication: a numbing agent to prevent the patient from feeling any vein discomfort from the subsequent medications.

- Third medication: a coma-inducing agent.

- Fourth medication: a muscle relaxant which stops breathing and heart function. It usually takes 2-6 min to stop the patient's heart.

MAID, medical assistance in dying; NS, Nova Scotia.

get it done. And so they don't take as long. I had one situation where I walked in and there was a party going on in the house. And I said, 'I'll go down to the back room,' where they wanted me, and I waited for two hours before the patient came into the room, and then performed the procedure. (Physician 10)

Where possible, a nurse (or clinician) inserts the two intravenous lines close to the procedure time to decrease having to reinsert them in dehydrated and very ill patients. Intravenous lines are not placed in patients with central (Hickman) or peripherally inserted central catheter [PICC] lines. A VON nurse inserts intravenous lines in long-term care. The nurse may stay for the procedure, if they are comfortable, if the patient/family wants them there and/or they have time. Some nurses will return for the procedure if the intravenous lines are placed earlier. Hospital nurses often arrive 1-2 hours before the procedure and stay with the family and body after MAID.

The clinician will draw up the syringes with medications (box 2). After determining the patient has the capacity to request MAID, the clinician explains the procedure including: what each medication does (if the patient wishes to know), the dying process and potential medication responses (ie, twitching). The clinician asks the patient if they wish to have MAID. If the patient says no, MAID does not occur. If the patient says yes, the clinician administers the medications over $10-15 \mathrm{~min}$. If a patient does not have the capacity to consent to MAID, the procedure does not occur, although this may change with the revised legislation.

A clinician may be delayed picking up the prescription if MAID is being rushed or a participating pharmacist cannot fill it. This can affect when the clinician arrives for the provision. How the clinician travels to the MAID location can also delay the process, especially if they are flying or driving. The MAID process can be stopped if the patient chooses not to have MAID or if the patient has lost capacity and cannot consent to the procedure. One physician described their time and compensation:

With an assessment and the charting and the procedure is probably about ... 6 to 8 hours of work in a month. ... it depends on the case too. Some are more straightforward than others. I would say it's about 8 hours of work. So I'd have to fit that in on weekends and evenings. ... But then the actual billing code right now, it's still capped at 2 hours for an assessment and 2 hours for a procedure. And almost all of my procedures have been longer. So I've just chosen to bill for 2 hours of my work and the rest is not paid. (Physician 1).

Another physician talked about being flexible:

When you go to do the procedure, it could be a 15 minute procedure and done, it could be multiple hours. So you sort of have to be willing to be flexible... have to make sure that whatever you had booked after you might not get to and you might get there - it just depends. (Physician 3)

Some NPs have had a different experience:

sometimes I'll do this on my off time. I try to include it in my day. My manager is very supportive of me doing this. ... I went ... to see a case, which is an hour away. But I do get reimbursed for my expenses. Mind you, it did take me a year to get my travel claim figured out.... The doctors get paid for doing this. The nurse practitioners don't. ... I think they're trying to lobby to get us paid. Like we get paid for our travel expenses. So I can send that in. But I know the physicians bill for doing a MAID case, like doing assessments. But we don't get paid. I mean you know, I'm going all hours of the day, the weekends, right. (Nurse Practitioner 3)

\section{Post-MAID—hospital in-patient or outpatient}

The clinician records the medications and time given, the patient's time of death and completes the death certificate. The clinician and/or nurse may wait with the family, participate in a family event or leave. Ward staff follow the protocols for postmortem care and although this may not be the usual process in many organisations, may contact security to transfer the body to the morgue. Or, the family may contact a funeral home to remove the body from the floor. The death certificate goes with the body. A manager or the hospital may provide staff debriefing. There may be delays waiting for the funeral home or security to collect the body, especially if they were not notified in advance of the death:

If you're doing them [MAID] in hospital after hours, we have to actually ask for security to come and take the body away. Or if you're at home, sometimes the family is not comfortable waiting there with the body themselves until the funeral home comes. So you have to hang around with them. We had one time here where the family did not want the body to go to the morgue. They didn't tell us that beforehand. ... We had to wait $31 \frac{1}{2}$ hours for the funeral home to come and pick the body up. (Physician 3)

\section{Post-MAID—non-hospital}

The clinician records the medications and time given, the time of death and completes the death certificate. The 
clinician and/or nurse may wait with the family, participate in a family event or leave. At home, the family will contact the funeral home to remove the body. In longterm care, the family, security or staff arrange for the funeral home to collect the body. The death certificate goes with the body. The family may want to spend time with the body before calling the funeral home and/ or may not have notified the funeral home in advance, which can lead to lengthy delays.

\section{Post-MAID after leaving setting}

The clinician documents the procedure and sends the MNN information including people present, medications given and dose, times the medication was pushed, time of death and notes about the procedure and/or family difficulties. They return all used and unused medications to the pharmacy, input information into the national MAID database online and may dictate notes. Some clinicians debrief with colleagues. Clinicians may bill Medical Service Insurance (MSI) up to 8 hours for MAID assessments and procedure. Clinicians send travel expenses to the MAA who submits these to NSH for reimbursement. Nurses are usually paid overtime by their organisation and typically debrief with a nursing manager/director but not always. The MNN collects and submits MAID statistics to the NSH and follows-up with the family, sometimes connecting them with community supports. The MNN and MAA collect and save MAID documentation and the MNN closes the case.

The pharmacy or practitioner disposes the used MAID medications. Some hospital pharmacies store and reuse the backup medications if they have not left their premises. Other pharmacies discard both sets of medications as they do not know how and where the medications were stored, what conditions they were exposed to, who they might have come into contact with and so on. One pharmacist detailed what happens with the medications:

ETC: 'So how would the physician or nurse practitioner dispose of what they had used?'

Pharmacist 3: 'That would go back to whatever their typical disposing protocol would be. There shouldn't be any leftover drug, I wouldn't think. So it would probably just need to be disposed of the vials and the packaging and that type of thing. So for us, we're only taking back drugs that haven't been opened or used at all.'

ETC: 'And then what happens on intake of the [MAID] kit?'

Pharmacist 3: 'We would just put it back. We would just disassemble the kit, put the drugs back. Except for one that's refrigerated that we have to dispose of ... It would only be stable for 30 days or so [after leaving the pharmacy]. ... We would just dispose of it.'

There may be delays with the physician entering data into the national registry and returning the MAID medications to the pharmacy. It takes them time to submit billing and travel reimbursement information and to receive reimbursement from NSH and MSI. Some clinicians have never been reimbursed for time or travel.

\section{DISCUSSION}

This study's flowchart process model indicates how multiple professionals work together and are involved at each stage of MAID. ${ }^{17-20}$ Clinicians, mainly working evenings and weekends, assess patient eligibility, write and pickup prescriptions, gather supplies and organise and provide MAID. Some clinicians are reimbursed, while others are not (eg, depending on their contract, some NP cannot be reimbursed for MAID and must participate outside working hours; some physicians provide MAID for free outside working hours). To compare, Medicare in Oregon pays for assisted suicide for terminally ill people with low income but does not specify who pays the physician for participating (eg, insurance companies). ${ }^{556}$ As well, physicians in the Netherlands are compensated by the patient's insurance company but Belgian physicians do not receive compensation. ${ }^{57}$ US patients pay from US $\$ 0-8000$ and there may be additional fees for medications, mileage and complex procedures (personal communication, Dr Lonny Shavelson, 2021). UK patients having assisted dying in Switzerland pay between $£ 6500$ and $£ 150000^{58}$ In Switzerland, physicians receive their regular wage and provide assisted dying during regular work hours (personal communication, Dr Erika Preisig, 2021). In Australia, physicians receive fee-for-service and provide assisted dying outside of regular work hours, typically in the patient's home (personal communication, Dr Alida Lancee, 2021). Nurses, often being paid overtime, support the patient and their supports before and after the procedure as well as insert intravenous lines. Health administrators organise the process as part of their workload. Pharmacists, within regular work hours, fill prescriptions and dispose of medications after MAID. The process differs slightly by location and in-patient/outpatient status. We identified multiple points where MAID could be delayed or stopped. ${ }^{19}$

Some NS processes were similar to others such as having a central coordinator, a variety of professionals being involved at different stages and MAID being available in multiple locations. ${ }^{9} 303133363759$ Some Ontario regions coordinate MAID centrally. ${ }^{45}$ Other processes were different such as not having a centralised pharmacy, clinicians making arrangements with patients and fewer health professions are involved (eg, no social workers, spiritual advisors, psychologists). ${ }^{30} 60$ Most MAID assessments and procedures are conducted on evenings and weekends, outside regular hours. Nurses are paid overtime for participating in MAID, unless it is during their regular shift. ${ }^{37}$ Some of our clinicians considered MAID 'volunteer work', since setting up billing codes and coordinating government and insurance payments can be difficult. ${ }^{35}$ Many devoted significant amounts of, mainly unpaid, time coordinating MAID but did not consider this sustainable. ${ }^{35}{ }^{36} \mathrm{NS}$ could learn from other provinces, including Manitoba where a single MAID team serves the entire province. ${ }^{61}$

Our clinicians learnt to ask about family dynamics to prevent difficult situations, such as arguments on the day 
of MAID or a wrongful death lawsuit. Thus, including spiritual providers, social and mental health professionals, psychiatrists and psychologists could be beneficial. ${ }^{49} 906-62$ Along with offering support, inserting the intravenous lines and documenting the process, our nurses want to meet patients and their supports before the day of MAID to get to know the person having MAID and in case there are family issues. ${ }^{3063}$ Pharmacy technicians in NS cannot prepare MAID medications; ${ }^{64}$ thus, pharmacists incorporate an additional 1-5hours into their regular workload. This is unusually long to fill a prescription. The Northwest Territories, Manitoba and Alberta have dedicated MAID pharmacies. ${ }^{65}$ Pharmacists do not provide MAID supplies (eg, tubing and syringes) and some clinicians scramble to collect or 'steal' supplies from their workplace. Some regions provide supplies with the MAID medications ${ }^{4}$ but some do not.

\section{Limitations}

This study occurred in one Canadian province and thus we cannot generalise to other provinces or internationally. ${ }^{667}$ However, the results could be helpful to other jurisdictions seeking to evaluate and improve MAID. Although this study has a smaller sample size for each group of professionals, ${ }^{68}$ we continued recruiting until no new information was found (ie, data saturation). To address sample and selection bias, as self-selected participants may not represent the views of all professionals, ${ }^{4568}$ we recruited across the province from different professionals during different times of the year.

\section{Implications for clinicians and policymakers}

This study builds on MAID research ${ }^{3-6}$ 26-28 30-32 344861 by detailing the process in NS from beginning to end. Our findings about the roles and activities of professionals could help inform MAID practice in the rest of Canada and internationally. We identified issues such as clinicians' additional time to pick up and drop off medications, travel to the patient, input data and bill hours. Other jurisdictions may consider the benefits of centrally coordinating communication between professionals and administrators to avoid miscommunication or missed communication.

Our identification of delays/stop points and resources are high priorities for improving MAID. Delays and stop points can limit patients' access to and receiving MAID. Resources include professionals' time and supplies. Providing assistance to set up reimbursement codes and processes could save clinicians' from using personal time without compensation. Having centralised coordination and a central pharmacy providing a MAID kit with medications and supplies are vital to help ensure delays are minimised and resources are used efficiently. If professional colleges allowed pharmacy technicians to assist with MAID prescriptions, this would significantly reduce pharmacists' time. Pharmacists' professional colleges should be concerned since their professionals are not compensated for hours of additional work to prepare and dispose MAID medications.

\section{Future research}

This study contributes to research about healthcare process models. Future researchers could compare and contrast process models from other jurisdictions with this study ${ }^{18}{ }^{45}$ which could be used to improve MAID internationally. To better understand each profession's contributions to and time for MAID, researchers could conduct participant observations to detail what they do throughout the process. Studies reveal a wide variety of professionals participate in MAID; $;^{38}$ hence, conducting interviews with them could provide further insights into the process. Since patients and their informal supports are involved throughout MAID, their insights could be added to improve the flowchart process model. As many jurisdictions are integrating patient-centred care, MAID administrators should consider the value of incorporating this approach.

\section{CONCLUSION}

This study adds knowledge about the variety of activities and roles that multiple professionals have throughout the entire MAID process in NS, Canada-these have not been studied in the international literature. Clinicians spend significant time to participate in and coordinate MAID. There are serious questions about the NS model's sustainability due to potential for burnout and clinicians ceasing to provide MAID since the model relies on them working additional (uncompensated) hours on evenings and weekends. Issues could also be raised about the ethics of sustaining a volunteer model which depends on unpaid work, personal time and inefficient workflow. The Nova Scotia College of Pharmacists should consider allowing pharmacy technicians to help prepare MAID medications as pharmacists also spend significant time preparing and checking MAID PPO. Our identification of where potential delays can occur can help clinicians, administrators and policymakers improve MAID and be of interest to other jurisdictions implementing it.

Acknowledgements The authors thank Izabela Panek, PhD for her assistance with figure 1.

Contributors ETC and SK conceived, designed, drafted and wrote the article, JY, GG, JM and NP critiqued, revised and edited it. All authors read and approved the final manuscript.

Funding This work was supported by: Dalhousie University SSHRC Explore Grant (\#37823), Dalhousie University Research Development Fund (\#48365), Rowe School of Business Research Grant (RRG2017-I002) and the Dalhousie Medical Research Foundation Bergmann-Porter Studentship.

Disclaimer None of the funders were involved in study design, collection, analysis and interpretation of the data or in writing the manuscript.

Competing interests None declared.

Patient consent for publication Not required.

Ethics approval The study was approved by the Nova Scotia Health Authority Research Ethics Board (Study Protocol ID: \#1022997)

Provenance and peer review Not commissioned; externally peer reviewed. 
Data availability statement All data relevant to the study are included in the article or uploaded as supplementary information. We do not have ethics approval to make raw data from this study available for sharing.

Supplemental material This content has been supplied by the author(s). It has not been vetted by BMJ Publishing Group Limited (BMJ) and may not have been peer-reviewed. Any opinions or recommendations discussed are solely those of the author(s) and are not endorsed by BMJ. BMJ disclaims all liability and responsibility arising from any reliance placed on the content. Where the content includes any translated material, BMJ does not warrant the accuracy and reliability of the translations (including but not limited to local regulations, clinical guidelines, terminology, drug names and drug dosages), and is not responsible for any error and/or omissions arising from translation and adaptation or otherwise.

Open access This is an open access article distributed in accordance with the Creative Commons Attribution Non Commercial (CC BY-NC 4.0) license, which permits others to distribute, remix, adapt, build upon this work non-commercially, and license their derivative works on different terms, provided the original work is properly cited, appropriate credit is given, any changes made indicated, and the use is non-commercial. See: http://creativecommons.org/licenses/by-nc/4.0/.

\section{ORCID iD}

Ellen T Crumley http://orcid.org/0000-0002-5198-6346

\section{REFERENCES}

1 National assembly of Quebec. Bill 52: an act respecting end-oflife care, 2013. Available: http://www.assnat.qc.ca/en/travauxparlementaires/projets-loi/projet-loi-52-40-1.html?appelant=MC

2 Justice Laws Website. An act to amend the criminal code and to make related amendments to other acts (medical assistance in dying), s.c. 2016 , c.3, 2016. Available: https://laws-lois.justice.gc.ca/ eng/annualstatutes/2016_3/fulltext.html

3 Health Canada. Fourth interim report on medical assistance in dying in Canada. Ottawa: Government of Canada, 2019. https://www. canada.ca/en/health-canada/services/publications/health-systemservices/medical-assistance-dying-interim-report-april-2019.htm

4 Ball IM, Hodge B, Jansen S, et al. A Canadian academic hospital's initial MAID experience: a health-care systems review. J Palliat Care 2019;34:78-84

5 Li M, Watt S, Escaf M, et al. Medical assistance in dying implementing a hospital-based program in Canada. N Engl J Med Overseas Ed 2017;376:2082-8.

6 Wiebe E, Green S, Wiebe K. Medical assistance in dying (MAID) in Canada: practical aspects for healthcare teams. Ann Palliat Med 2021;10:3586-3593.

7 Downar J, Fowler RA, Halko R, et al. Early experience with medical assistance in dying in Ontario, Canada: a cohort study. Can Med Assoc J 2020;192:E173-81.

8 Brooks L. Health care provider experiences of and perspectives on medical assistance in dying: a scoping review of qualitative studies. Can J Aging 2019;38:384-96.

9 Fujioka JK, Mirza RM, McDonald PL, et al. Implementation of medical assistance in dying: a scoping review of health care providers' perspectives. J Pain Symptom Manage 2018;55:1564-76.

10 Hune-Brown N, Mora L. The doctors who assist in suicide on what it's like to end a life. Toronto Life, 2017. Available: https://torontolife. com/city/life/doctors-assist-suicide-like-end-life/

11 Tutton M. Nova Scotia doctors report barriers to assisted-dying requests. The globe and mail, 2017. Available: https://www. theglobeandmail.com/news/national/nova-scotia-health-agencyreports-barriers-to-assisted-dying-requests/article36375847/

12 McDonald C. Toronto woman raising awareness about medical assistance in dying days before she plans to end her life. Global News [Internet], 2019. Available: https://globalnews.ca/news/ 5246430/medical-assistance-in-dying-canada-violeta-mikaia/

13 Ipsos. Support for medically-assisted dying in Canada. Ottawa: Dying with Dignity, 2020. https://www.dyingwithdignity.ca/irpoll_results_ 2020

14 Bissett K. Audrey Parker's message to Canadians, days before dying with medical assistance. The Canadian Press, 2019. Available: https://www.ctvnews.ca/canada/audrey-parker-s-message-tocanadians-days-before-dying-with-medical-assistance-1.4286147

15 Lajoie G. Québec veut étendre l'aide médicale mourir. L'actualité, 2019. Available: https://www.journaldequebec.com/2019/05/29/ quebec-veut-etendre-laide-medicale-a-mourir

16 Justice Canada. Government of Canada proposes changes to medical assistance in dying legislation [Internet], 2020. Available: https://www.canada.ca/en/department-justice/news/2020/02/ government-of-canada-proposes-changes-to-medical-assistance-indying-legislation.html [Accessed Cited 15 Dec 2020].

17 Reay T, Goodrick E, Waldorff SB, et al. Getting leopards to change their spots: co-creating a new professional role identity. AMJ 2017;60:1043-70.

18 Langley A. Strategies for theorizing from process data. AMR 1999;24:691-710.

19 Cloutier C, Langley A. What makes a process theoretical contribution? Organization Theory 2020;1:263178772090247-32 https://doi.org/10.1177\%2F2631787720902473

20 Van De Ven AH, Poole MS. Explaining development and change in organizations. AMR 1995;20:510-40.

21 White BP, Willmott L, Close E. Victoria's voluntary assisted dying law: clinical implementation as the next challenge. Med J Aust 2019;210:207-9.

22 Death with Dignity. Death with dignity acts. n.d. Available: https:// www.deathwithdignity.org/learn/death-with-dignity-acts/

23 My Death My Decision. Assisted dying in other countries, 2018. Available: https://www.mydeath-mydecision.org.uk/info/assisteddying-in-other-countries/

24 Hollander MJ, Miller JA, Kadlec H. Evaluation of healthcare services: asking the right questions to develop new policy and programrelevant knowledge for decision-making. Healthc Q 2010;13:40-7.

25 Brown J, Goodridge D, Harrison A. Care considerations in a patientand family-centered medical assistance in dying program. J Palliat Care 2020;825859720951661

26 Hales BM, Bean S, Isenberg-Grzeda E, et al. Improving the medical assistance in dying (MAID) process: a qualitative study of family caregiver perspectives. Pall Supp Care 2019;17:590-5.

27 Oczkowski SJW, Crawshaw D, Austin P, et al. How we can improve the quality of care for patients requesting medical assistance in dying: a qualitative study of health care providers. J Pain Symptom Manage 2021;61:513-21.

28 Variath C, Peter E, Cranley L, et al. Relational influences on experiences with assisted dying: a scoping review. Nurs Ethics 2020;27:1501-16.

29 Hogg S, Nippak P, Spalding K. Implementation of medical assistance in dying: an evaluation of clinician knowledge and perceptions at a large urban multi-site rehabilitation centre in Toronto. $J$ Hosp Adm 2018;7:41-9.

30 Beuthin R, Bruce A, Scaia M. Medical assistance in dying (MAiD): Canadian nurses' experiences. Nurs Forum 2018;53:511-20.

31 Downar J, Green S, Radhakrishnan A, et al. An entrustable professional activity descriptor for medical aid in dying: a mixedmethods study. CMAJ Open 2018;6:E657-63.

32 Oczkowski SJW, Ball I, Saleh C, et al. The provision of medical assistance in dying: protocol for a scoping review. BMJ Open 2017;7:e017888.

33 Wu JSY, Pinilla J, Watson M, et al. Medical assistance in dying for cancer patients one year after Legalization: a collaborative approach at a comprehensive cancer centre. Curr Oncol 2018;25:e486-9.

34 Shaw J, Wiebe E, Nuhn A, et al. Providing medical assistance in dying: practice perspectives. Can Fam Physician 2018;64:e394-9.

35 Khoshnood N, Hopwood M-C, Lokuge B, et al. Exploring Canadian physicians' experiences providing medical assistance in dying: a qualitative study. J Pain Symptom Manage 2018;56:222-9.

36 Wilson DM, Triscott JAC, Cohen J, et al. Educational needs of healthcare professionals and members of the general public in Alberta Canada, 2 years after the implementation of medical assistance in dying. Health Soc Care Community 2019;188.

37 Silvius JL, Memon A, Arain M. Medical assistance in dying: Alberta approach and policy analysis. Can J Aging 2019;38:397-406.

38 CAMAP. Publications: clinical guidance documents for maid. Victoria bc, n.d. Available: https://camapcanada.ca/publications/

39 Zworth M, Saleh C, Ball I, et al. Provision of medical assistance in dying: a scoping review. BMJ Open 2020;10:e036054.

40 Canadian Institute for Health Information. Medical assistance in dying: key priorities and opportunities - proceedings report, 2017. Available: https://www.cihi.ca/sites/default/files/document/maidproceedings-report-en.pdf

41 Canadian Institute for Health Information. Medical assistance in dying: information needs for health systems and public reporting: discussion forum report, 2017. Available: https://www.cihi.ca/sites/ default/files/document/MAID-proceedings-en.pdf

42 Frolic A, Harper W, Dees M. Expanded rights to medical assistance in dying are pointless without better support for MAID providers: widening legal access to MAID could reduce the number of health care professionals willing to provide it. CBC News Opinion, 2020. Available: https://www.cbc.ca/news/opinion/opinion-assisted-dyingMAID-legislation-medical-providers-1.5459942 
43 Nova Scotia Health Authority. Medical assistance in dying, 2019. Available: http://www.nshealth.ca/about-us/medical-assistancedying

44 Jun GT, Ward J, Morris Z, et al. Health care process modelling: which method when? Int J Qual Health Care 2009;21:214-24.

45 Goodman LA. Snowball sampling. Ann. Math. Statist. 1961;32:148-70.

46 Fontana A, Frey JH. Interviewing: the art of science. In: Denzin NK, Lincoln YS, eds. Handbook of qualitative research. Thousand Oaks, CA: Sage, 1994: 361-76.

47 Rolfe G, Validity RG. Validity, trustworthiness and rigour: quality and the idea of qualitative research. J Adv Nurs 2006;53:304-10.

48 Brown JB, Ryan BL, Thorpe C. Processes of patient-centred care in family health teams: a qualitative study. CMAJ Open 2016;4:E271-6.

49 Malterud K. Qualitative research: standards, challenges, and guidelines. Lancet 2001;358:483-8.

50 Kuckartz U. Qualitative text analysis: a guide to methods, practice and using software. Los Angeles: SAGE, 2014.

51 Selby D, Bean S, Isenberg-Grzeda E, et al. Medical assistance in dying (MAID): a descriptive study from a Canadian tertiary care hospital. Am J Hosp Palliat Care 2020;37:58-64.

52 Wiebe E, Shaw J, Green S. Reasons for requesting medical assistance in dying. Can Fam Clinician 2018;64:674-9.

53 Nuhn A, Holmes S, Kelly M. Experiences and perspectives of people who pursued medical assistance in dying: qualitative study in Vancouver, bc. Can Fam Clinician 2018;64:e380-6.

54 Dying with Dignity. About, 2020. Available: https://www. dyingwithdignity.ca

55 The Associated Press. Oregon LETS state pay for suicides. the new York times: A10, 1998. Available: https://www.nytimes.com/1998/02/ 27/us/oregon-lets-state-pay-for-suicides.html

56 Death with Dignity. Frequently asked questions, 2021. Available: https://www.deathwithdignity.org/faqs/
57 Van Wesemael Y, Cohen J, Bilsen J, et al. Implementation of a service for physicians' consultation and information in euthanasia requests in Belgium. Health Policy 2012;104:272-8.

58 Riley L. The true cost: how the UK outsources death to Dignitas. Campaign for Dignity in Dying, 2017. Available: https://features. dignityindying.org.uk/true-cost-dignitas/

59 Manitoba. Medical assistance in dying. health, seniors and active living. n.d. Available: https://www.gov.mb.ca/health/MAID.html

60 Sears SR, Stanton AL. Physician-Assisted dying: review of issues and roles for health PSYCHOLOGISTS. Health Psychol 2001;20:302-10.

61 Klowak M. Medically assisted dying team in Manitoba doubles in size. CBC News, 2017. Available: https://www.cbc.ca/news/canada/ manitoba/assisted-death-MAID-team-brock-wright-1.3927556

62 Rousseau S, Turner S, Chochinov HM, et al. A national survey of Canadian psychiatrists' attitudes toward medical assistance in death. Can J Psychiatry 2017;62:787-94.

63 Pesut B, Thorne S, Stager ML, et al. Medical assistance in dying: a review of Canadian nursing regulatory documents. Policy Polit Nurs Pract 2019;20:113-30.

64 Nova Scotia College of Pharmacists. Standards of practice: medical assistance in dying, 2016. Available: https://www.nspharmacists.ca/? page $=$ standardsofpractice\#SOPMAiD

65 Verweel L, Rosenberg-Yunger ZRS, Movahedi T, et al. Medical assistance in dying: examining Canadian pharmacy perspectives using a mixed-methods approach. Can Pharm J 2018;151:121-32.

66 Kemper EA, Stringfield S, Teddlie C. Mixed methods sampling strategies in social science research. In: Tashakkori A, Teddle C, eds. Handbook of mixed methods in social and behavioral research. Thousand Oaks, CA: Sage, 2003: 273-96.

67 Leung L, Validity LL. Validity, reliability, and generalizability in qualitative research. J Family Med Prim Care 2015;4:324-7.

68 Martínez-Mesa J, González-Chica DA, Duquia RP, et al. Sampling: how to select participants in my research study? An Bras Dermatol 2016;91:326-30. 